\title{
Teaching Anatomy in the Multimedia World-Using Digital Tools for Progressive Learning over Time
}

\author{
Marcus Granmo, Fredrik Bengtsson \\ Department for Experimental Medical Sciences, Lund University, Lund, Sweden \\ Email: marcus.granmo@med.lu.se
}

Received 20 April 2015; accepted 23 June 2015; published 26 June 2015

Copyright (C) 2015 by authors and Scientific Research Publishing Inc.

This work is licensed under the Creative Commons Attribution International License (CC BY). http://creativecommons.org/licenses/by/4.0/

(c) (i) Open Access

\section{Abstract}

In a cross-faculty project journalism students filmed anatomy briefings on a medical program. The material gave medical students free access to rehearse and repeat over time. The journalism students on their part practiced camera technique, directing and editing: It was an opportunity for students to help students. Following a quality evaluation of undergraduate studies at the Lund University medical faculty in 2011, we explored, developed, and implemented novel educational tools to meet students' need in the multimedia world in which they operate. Incorporating complementary digital learning resources, in particular integration with mobile applications enabled us to meet students in their own world, thereby enhancing the learning process. We produced short video clips on specific anatomic themes, following the curriculum of the well-established anatomy course, and posted them online, allowing continuous rehearsal and repetition over time at a pace that suits individual students. Also, available to all semesters it provides free opportunities for repetition, reducing the risk of knowledge-loss between basic and clinical parts of the program. Besides the obvious benefits for students, the material gave teachers a clear view of the students' curriculum. Thus, the material can be used for alternative, more interactive forms of examination. The paper describes the project, and the results from evaluations and integration with mobile technology.

\section{Keywords}

Multimedia, Flipped Classroom, Mobile Technology, Cross-Faculty, Medicine

\section{Introduction}

This paper describes a cross-faculty project at Lund University where part of the teaching in medical anatomy is 
filmed and produced as short movie clips that are made freely available to all students.

The second semester of the Medical program at Lund University "The nervous system and the musculoskeletal system" contains both neuroscience and a large part of the basic anatomy on the medical program. This includes a wide variety of anatomical structures (approx. 1500 structures in Latin) to be learned in parallel with studies on the brain and nervous system. For many years, anatomy briefings on various themes, such as upper or lower extremity, have been performed where students from the higher semesters teach a small group of students using plastic anatomical models. Although the briefings are much appreciated, many students perceive them as stressful and that each briefing is too extensive. Free access to the anatomical models is however granted for self-studies. Alongside this, there are cathedral lectures and problem based learning sessions mainly covering the functional aspects of anatomy. This, together with traditional self-studies by aid of the recommended literature, completes the anatomy teaching, a layout launched after a major revision of the medical program in the mid 90s (Utbildningen i makroanatomi-Den framtida morfologiundervisningen i Lund, 1994). In general, the students find anatomy to be interesting and highly relevant for their future profession and good examination results prove this. Nevertheless, we have for a long time felt a general lack of understanding of the functional aspects of anatomy. This is reflected by shortcomings in the results on clinical semesters where many students fail in the introduction exam. As it turns out, most students lack a simple tool to repeat and rehearse their knowledge and thus are not adequately prepared when facing the exam.

The second semester at the medical program is in many ways extra challenging from a student perspective. After a more or less introductory first semester and still to a large extent unaccustomed to University studies, the students face their first full semester course containing a large curriculum. This has brought us to the conclusion that active student-oriented tools are needed to facilitate learning for those in direct need of help to reach the learning objectives, to push all students towards a higher level of understanding of the curriculum, and to broaden their academic knowledge (Michael, 2006; Prince, 2004). Our recipe for this has been multifaceted. We have introduced lectures covering a broader range than the course objectives, such as pre-historic osteoporosis from an archaeological perspective, the role of Latin in medical history, torso training from an elite athlete's point of view, evening school with Latin grammar, etc. We have also used flipped classroom tools to make students more active and take responsibility for their own learning. PeerWise, an online tool that turns students into teachers writes multiple-choice questions with explanations, thus generating their own assessments. This example of crowd sourcing is a powerful tool for facilitating the students' learning (Jones, 2010). Activating students and making them creators or co-producers of parts of their own teaching are intriguing trends in the future (NMC Horizon Report 2014-Higher Education Edition, 2014; "Three Trends That Will Influence Learning and Teaching in 2015, 2014). PeerWise has been highly popular and has been proven to facilitate deep learning (Bates, Galloway, Riise, \& Homer, 2014; Bottomley \& Denny, 2011). The students' use of web-based tools also increases the use of the course homepage, thus guiding the students towards the quality-controlled content instead of free-ranging the Internet for un-scrutinised information. By using digital tools, we can at a small cost complement the traditional teaching methods with multimedia content, offering a broader range of learning tools, and providing a constant source for repetition and rehearsal during the course as well as among semesters during the whole medical program. A first target for this digitization has been the descriptive parts of the anatomy curriculum. To learn and understand approximately 1500 structures in correct Latin is a hard task for any fresh student and to fire-hose the students at teacher-led demonstrations risks creating a cognitive overload. By producing an online kit of multimedia material, we can make the students prepare in advance for the teacher-led demonstrations. These demonstrations can then focus on problem solving, explanation and discussions, thus optimizing the use of the teacher-student interaction.

\section{Project}

The project started with the forming of a cross-faculty project group with students and teachers from the journalism program together with amanuensis from higher semesters on the medical program. Some key elements of the process and finished product were established from the start. First, an important feature was to create a material directly adapted to the course curriculum. This makes it even easier for the fresh students to take in and retain the knowledge. Second, the finished material should be divided in short movie clips to fit with the current consensus that the attention span when viewing multimedia material is limited to as little as a few minutes (Bunce, Flens, \& Neiles, 2010; Dufault \& Frey, 2013; Szpunar, Moulton, \& Schacter, 2013). Third, the student 
themselves should be responsible for both presentation and filming of the material. This will increase the credibility of the material towards the students of the course and clearly display the rapid knowledge development of their fellow classmates at the higher semesters. Also, this is economically beneficial for the Faculty. The medical student amanuensis got to practice teaching, script writing and planning. The journalism students on their part got to practice camera technique, cutting and editing and even got to learn some anatomy in the process. Fourth, the material should be freely available and easy to access. A simple structure of the user interface together with a minimal amount of mouse clicks to access the desired content is in our view a key element for reaching all students. Fifth and finally, it was important to integrate the movie clips together with other digital course material in a complete and simple platform/package. Especially, we wanted this to be available on mobile platforms for maximum impact with the students.

It was clear from the start that to create the best material we needed to film the amanuensis separate and not with the students present. Only then could the participants rehearse and make multiple takes until the material reached the desired quality. After this, the filming was started. The plastic anatomical models were the same as normally used by the medical students. The journalism program provided all equipment needed for filming. Filming was done mainly after 6 am and during weekends. In total, approximately 40 hours was spent filming and 45 hours editing. Additionally the amanuensis spent around 10 hours preparing for the sessions. Except for the first session, where all project personnel were present, the students performed all filming themselves.

In parallel to filming, a user-friendly interface was created in LibGuides, a simple digital course platform available from the University library. This enabled us to get user statistics of the individual movie clips. Also, user evaluations for both students and teachers can easily be created. The material was divided into topics under which the individual film clips can be chosen. Figure 1 shows a screenshot of the finished movie platform. The organization follows the teacher-led demonstrations as well as the students' list of anatomical structures. As the filmed material was being completed, the next issue was where to store the data files as well as how to avoid that the material could be downloaded and spread elsewhere. This is a common concern when dealing with digital course material. In many ways we see benefits with completely open source thinking, but in this particular case the "actors" were a bit reluctant to the idea of freely releasing the material. Also, we needed clear user statistics from the course students and this would obviously be corrupted with content spread. After discussions we ended up with a solution with a password-protected platform and embedded movie clips with the source code

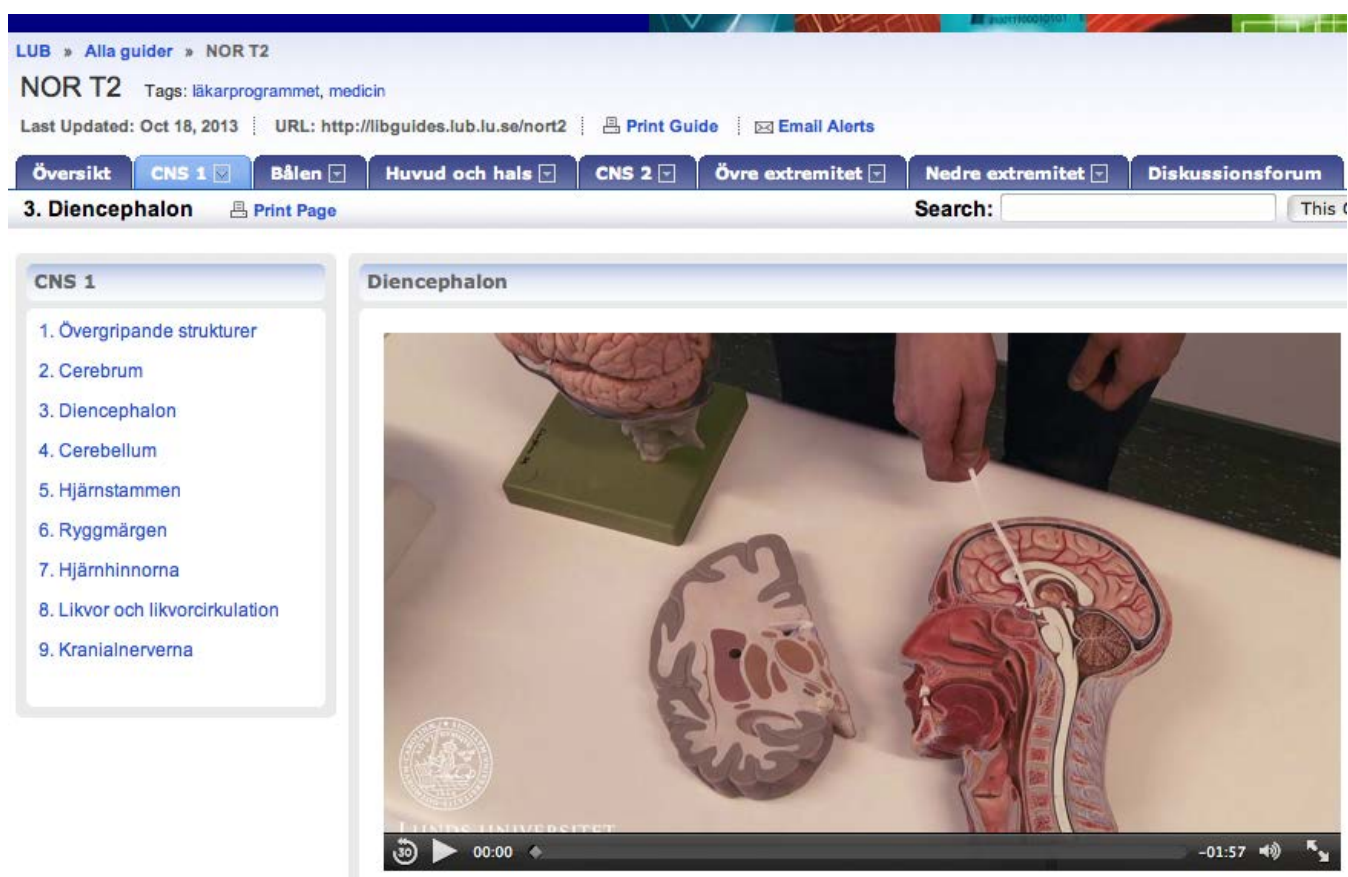

Figure 1. A screen shot of the finished digital movie platform. Clicking on the individual scroll list allows easy access to each theme/topic. The material was organized directly after the anatomy compendium of the course. 
occluded. We also discussed the issue of content spread with the students of the course and they understood the reasons behind our concerns. However, as the material is easily available on the digital platform, we foresaw no significant risk of content spread.

Quality control was incorporated from the start of the project. First, the amanuensis themselves examined the material when filming and editing. Second, a group of teachers checked the material before launch. And third, the students using the material naturally provide a continuous, on-going quality control. Hereby, some minor issues were identified and could be corrected. Via the digital platform the students can discuss and post questions about the content, thus creating a forum for collaboration and problem solving. Hereby, the students have resolved questions about the content as well as supplied ideas for improving the material. Also, teachers are encouraged to take active part in the discussions. This on-going dialogue between students and teachers was an important part of the project.

A most important part of the project was to obtain user statistics. Besides the data generated automatically by the digital platform, we created evaluation forms for both students and teachers. The questions covered both technical aspects of the platform structure and movie clips as well as user-directed questions. A separate form was created for teachers with questions mostly regarding the quality of the content.

The complete material was launched at the start of the fall semester 2013 and was immediately embraced by the students. The first week, the platform was the most visited LibGuide on the whole Lund University (Figure 2), a good indicator of the need for this kind of educational tools. The material was used throughout the semester and the students used the platform also during course weeks that did not incorporate any direct anatomy. Taking a more thorough look at the statistics we could observe a few key points (Figure 3). First, it was clear that activity peaked during the anatomy-intense weeks. We also noticed that the students were active before the teacher led demonstrations and thus, as we had predicted, use the material in preparation for these situations - i.e. a classic example of flipped classroom. Second, it was clear that most students focused on the anatomical themes that were directly relevant for the impending course week. Movie clips focused on later themes were however mostly ignored. Third, as expected, platform use peaked the last week before the anatomy exam but students also used the material ahead of the written exam at the end of the semester. This was somewhat surprising due to

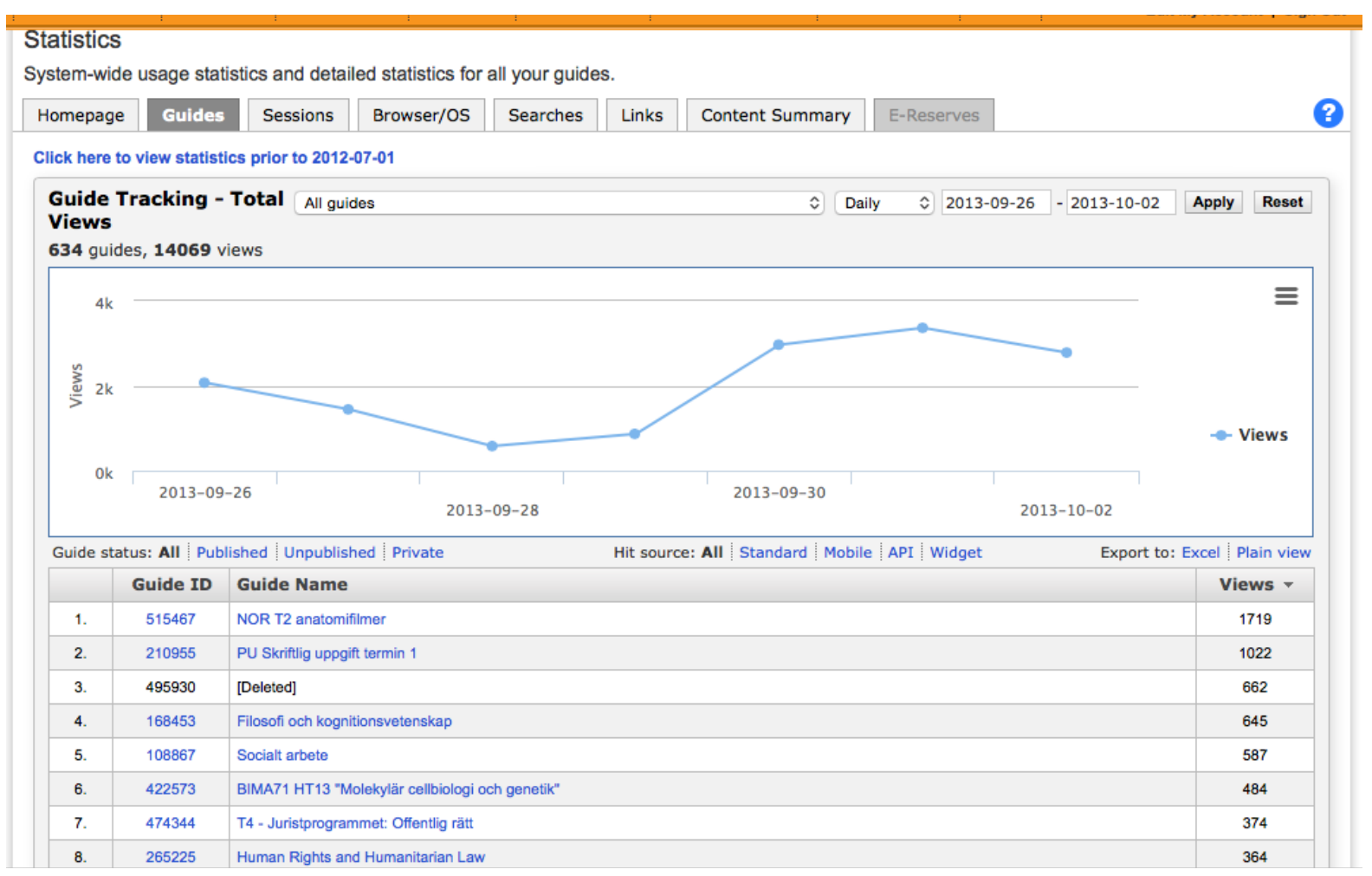

Figure 2. At launch, the digital anatomy movie platform (NOR T2 anatomifilmer) is the most visited LibGuide on all Lund University. 


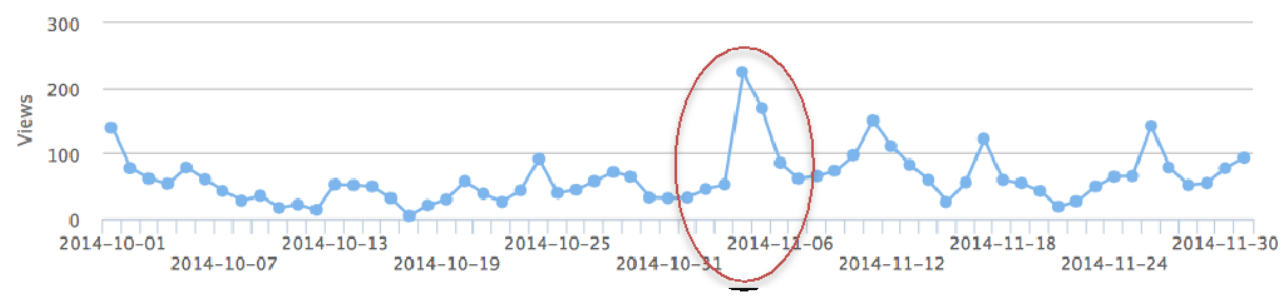

NOR H14: Schema kursvecka 10 (v 45-46)

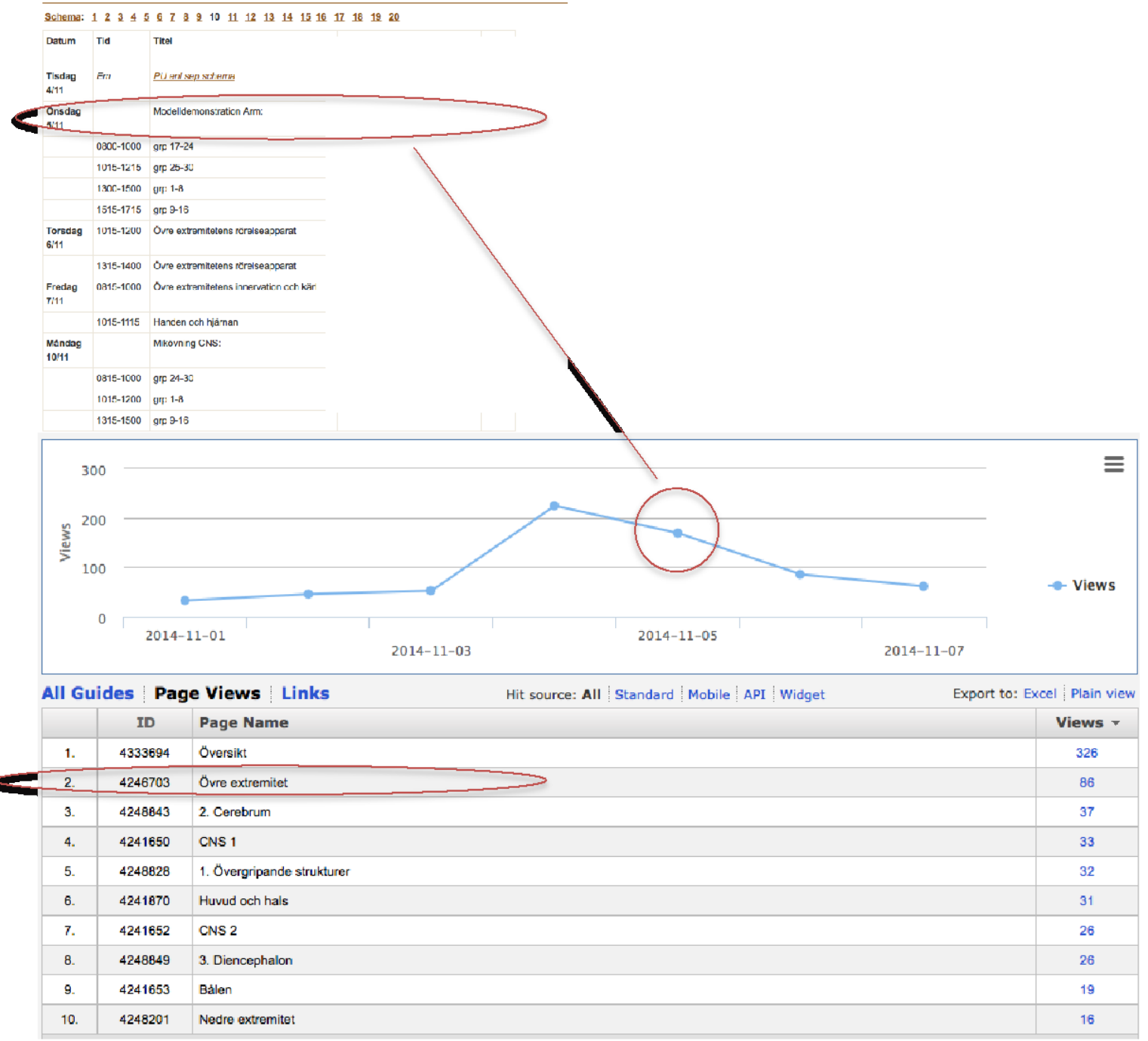

Figure 3. Statistics show that the students use the material to prepare for teacher-led demonstrations, mainly focusing on the material relevant for the upcoming weekly theme. Upper part, statistics from one month. Middle part, schedule for one course week with highlighted teacher-led anatomy demonstration of the upper extremity ("ModelldemonstrationArm"). Lower part, statistics from the same course week clearly showing that the students' activity is peaking ahead of the teacher-led demonstrations as well as the following full class lectures (on Thursday and Friday). Most views are seen for the movie clip on the upper extremity "Övreextremitet". Also, preparative activity can be seen ahead of the upcoming CNS microscopy demonstration ("Mikövning CNS").

the fact that the anatomy content of the written exam is focused on functional aspects instead of the descriptive parts of the movie clips. Thus, the students seem to use the movies also to explain the functional aspects of the subject. 
As mentioned above, we constructed simple evaluation forms embedded within the platform. Surprisingly, almost all students (124 of 126) filled in the form and the results were overwhelmingly positive. Figure 4 shows a summary of the user responses. From this data we could conclude that the material was well appreciated by the students, that the movie quality is adequate, the web platform work well and that most student feel that the material is helpful to keep their anatomy knowledge up to date during the semester as well as a future source of repetition for upcoming semesters. Very similar data has been obtained for the 2013 and 2014 semesters. Figure 5 displays user statistics for 3 consecutive semesters showing similar student activity patterns. Since the spring

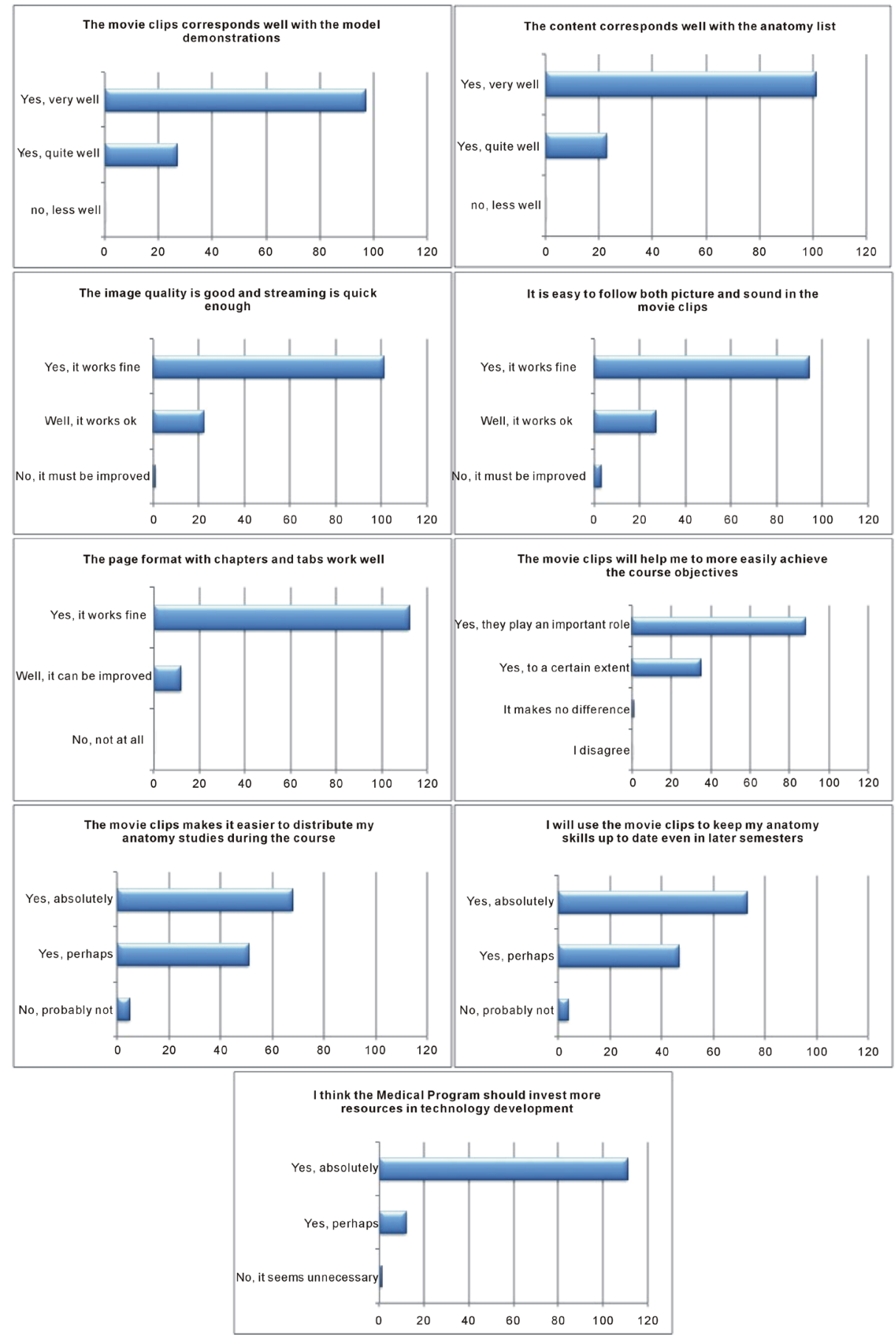

Figure 4. A summary of the responses from the students' evaluation form. 


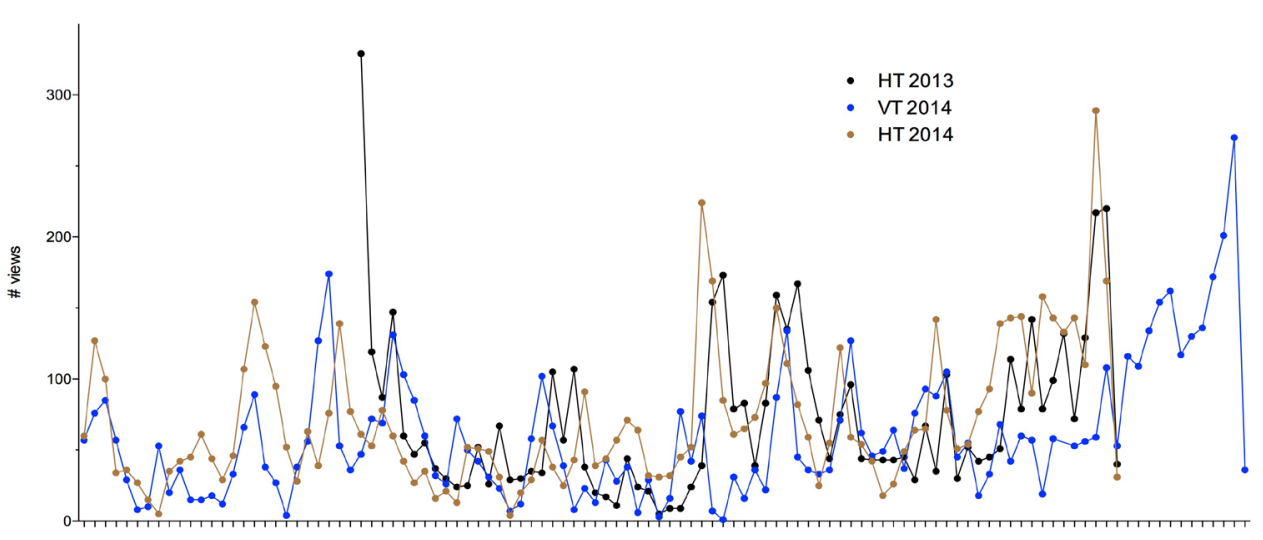

Figure 5. User statistics from three semesters showing similar activity pattern of the students (note: spring semester 2014 (VT 2014) was 10 days longer).

semester of 2014 the material has been freely available for all semesters of the medical program. Many students from later clinical parts of the education have reported that they use the material to prepare for specific clinical situations as well as directly in teaching situations such as case discussions. During 2015 the first students who have had access to the movie clips from the start will reach the clinical parts of the program and we will of course follow up on their experience of knowledge-loss and assessment results to try and measure the impact of the material.

In a separate project we have developed a simple, free mobile application for the students to have access to the course schedule and through which we can contact the students. This project was also made in collaboration with the medical students, some of which work part time developing mobile applications. One of the key aspects when designing the app was to create a flexible module that easily could be expanded with additional digital course material. Hence, as soon as the anatomy movie clips were up and running we started the work to embed them also in the mobile app. This created some extra work with resolution and adaptation to the mobile format. The updated application was launched for the 2014 fall semester. Approximately $85 \%$ of the students have mobile phones that allow them to use the application and we expect the number of students that use the filmed anatomy clips through their mobile devices to be approximately the same; the possibility to study anatomy whenever, wherever and only two "clicks" away is greatly appreciated by the students. In the next step we will include libraries for digital histology slides and lecture hand-outs in the app. Although the medical program in Lund only lately introduced a more complete digital learning platform (Moodle) where all course material is gathered, we foresee that the in-house mobile application will be a much-used complement due to the availability and simplicity of the design. Since the start of this project, several spin-offs with cross-faculty student collaborations have arisen within Lund University and the students themselves have even organised a central education development support group to facilitate contact between teachers and students from different faculties. From our part, we foresee a continuous collaboration between the journalism and medical programs in the future.

\section{Conclusion}

In conclusion, by developing and incorporating digital multimedia as a complement to traditional teaching material, we can broaden the possibilities to increase the students' learning (Boye, Moen, \& Vik, 2012). It is important to emphasise that digital material should be used as a complement and not a replacement for teacher-led activities (Prescott, Norcini, McKinlay, \& Rennie, 2002). By broadening the palette of learning tools, we give all students a chance to choose their individual unique learning path albeit with the risk of increasing the cognitive load (Calderwood, Ackerman, \& Conklin, 2014). Also, with freely available digital material flipping the classroom, we can direct the student-teacher interactions to focus more on problem solving and complex issues of the curriculum, thus hopefully deepening the learning process. Furthermore, it is also a good solution to minimize knowledge loss between the preclinical semesters and the clinical parts of the program. Especially when containing neuroanatomy, it can help avoid the well-known fear of neurobiological diseases and neurology, the socalled Neurophobia, common among medical students (Szirmai, 2012). Finally, making students co-producers 
of the learning tools makes the material more credible, more economical and often more user-oriented, which is a clearly visible proof of the possibilities of making students co-producers of their education.

\section{Acknowledgements}

This project was sponsored by educational development funds from the medical program at Lund University.

\section{References}

Bates, S. P., Galloway, R. K., Riise, J., \& Homer, D. (2014). Assessing the Quality of a Student-Generated Question Repository. Physical Review Special Topics-Physics Education Research, 10, Article ID: 020105. http://dx.doi.org/10.1103/PhysRevSTPER.10.020105

Bottomley, S., \& Denny, P. (2011). A Participatory Learning Approach to Biochemistry Using Student Authored and Evaluated Multiple-Choice Questions. Biochemistry and Molecular Biology Education, 39, 352-361. http://dx.doi.org/10.1002/bmb.20526

Boye, S., Moen, T., \& Vik, T. (2012). An e-Learning Course in Medical Immunology: Does It Improve Learning Outcome? Medical Teacher, 34, e649-e653. http://dx.doi.org/10.3109/0142159X.2012.675456

Bunce, D. M., Flens, E. A., \& Neiles, K. Y. (2010). How Long Can Students Pay Attention in Class? A Study of Student Attention Decline Using Clickers. Journal of Chemical Education, 87, 1438-1443. http://dx.doi.org/10.1021/ed100409p

Calderwood, C., Ackerman, P. L., \& Conklin, E. M. (2014). What Else Do College Students "Do" While Studying? An Investigation of Multitasking. Computers and Education, 75, 19-29. http://dx.doi.org/10.1016/i.compedu.2014.02.004

Dufault, C., \& Frey, G. (2013). Are You with Me? Measuring Student Attention in the Classroom. The Teaching Center Journal. http://teachingcenter.wustl.edu/Journal/Reviews/Pages/student-attention.aspx - .VBALzCgsIqQ

Jones, J. B. (2010). Exam Questions: Outsourcing vs. Crowdsourcing. The Chronicle of Higher Education. http://chronicle.com/blogs/profhacker/exam-questions-outsourcing-vs-crowdsourcing/28911

Michael, J. (2006). Where's the Evidence That Active Learning Works? Advances in Physiology Education, 30, $159-167$. http://dx.doi.org/10.1152/advan.00053.2006

NMC Horizon Report 2014-Higher Education Edition (2014). NMC Horizon Report.

Prescott, L. E., Norcini, J. J., McKinlay, P., \& Rennie, J. S. (2002). Facing the Challenges of Competency-Based Assessment of Postgraduate Dental Training: Longitudinal Evaluation of Performance (LEP). Medical Education, 36, 92-97. http://dx.doi.org/10.1046/j.1365-2923.2002.01099.x

Prince, M. (2004). Does Active Learning Work? A Review of the Research. Journal of Engineering Education, 93, $223-231$. http://dx.doi.org/10.1002/j.2168-9830.2004.tb00809.x

Szirmai, I. (2012). Neurophobia. Ideggyogy Sz, 65, 221-228.

Szpunar, K. K., Moulton, S. T., \& Schacter, D. L. (2013). Mind Wandering and Education: From the Classroom to Online Learning. Frontiers in Psychology, 4, 495. http://dx.doi.org/10.3389/fpsyg.2013.00495

Three Trends That Will Influence Learning and Teaching in 2015 (2014). https://onlinelearninginsights.wordpress.com/2014/12/29/three-trends-that-will-influence-learning-and-teaching-in-2015/

Utbildningen i makroanatomi-Den framtida morfologiundervisningen i Lund (1994). Den framtida morfologiundervisningen $i$ Lund. Lund: Lunds Universitet. http://mfskane.se/uploads/Bilaga\%201,\%20Utbildningen\%20i\%20makronanatomi\%20i\%20Lund.pdf 